\title{
Research on Investment Risk Warning of Technology Innovation in High-tech Enterprises
}

\author{
Zhongmin Ma \\ Management School of Xu Zhou Institute of Technology, Xuzhou, 221008, \\ China
}

\begin{abstract}
Technology innovation of high tech enterprises is a coexistence process of success and risk. It can prevent or reduce the investment risk and improve the success rate to accurately predict the investment risk. This paper constructs the index system of investment risk of technology innovation in high-tech enterprises. In addition, this paper also gives the countermeasures to prevent the investment risk of technology innovation in high-tech enterprises.

Keywords: investment risk warning, technology innovation, high-tech enterprises
\end{abstract}

\section{Introduction}

Technology innovation is the driving force for the development of high tech enterprises. The success of technological innovation will bring great benefits to the high-tech enterprises. However, due to the systematic and complex characteristics of the process of technological innovation, it has become a highrisk activity. Many high-tech enterprises fail to achieve technological innovation. But there are also some enterprises due to the success of technological innovation to obtain high profits, and has made the industry leader. In fact, the accuratepredictof investment risk of technological innovation can effectively control the overall risk of enterprises can greatly reduce the investment decision of enterprise technology innovation project management and the risk of blindness. Risk assessment methods have different defects, predict the project risk value is not necessarily correct, but the lack of technology innovation based on project risk investment decision criteria, to objectively evaluate the risk value of a project 
level. The potential high risk and high return are the remarkable characteristics of high tech innovation. The higher the degree of innovation, uncertainty is greater, the greater the risk of potentially higher income of course, if the enterprise because of fear of risk, fear of failure, and less risk of project implementation, although this can reduce the possibility of failure of enterprise technical innovation, but also the loss of a certain extent the greater revenue opportunities. It is a viable investment plan to select the medium risk of innovation and pay attention to the risk early warning.

\section{Indexes construction of investment risk warning of technology innovation}

\subsection{General thinking}

In the process of technology innovation risk, warning indexes selection is the basis of risk early warning management. Whether the risk identification and evaluation results are correct or not will determine the success or failure of technological innovation to a large extent. In order to ensure the risk identification is scientific and reasonable, and can fully and objectively reflect the risk of technology innovation level, based on a lot of literature on the research results, through expert interviews and field research, put forward about the potential risk of enterprise technology innovation as a result of the initial hypothesis of. This paper identifies the risk factors of technological innovation from the aspects of technical risk, decision-making risk, market risk and environmental risk.

\subsection{Indexes construction of technology risk}

Technical risk refers to the technical factors in the development of technology projects and the risks associated with the development of technology. At the beginning of the formation of new technology, may be very rough, immature, but for the existing technical conditions can be quickly improved, developers and the main body of innovation will not be fully grasp. Therefore, for some technologies, the development prospects of how, there is uncertainty. Whether a technology can achieve the desired goal is not determined before the development of technological innovation and in the process. Market competition makes it a common thing to replace each other. Technical products may also be replaced by newer technologies and products at any time. We select three indexes as the technology risk indexes. $I_{1}$ : technology accumulation level; $I_{2}$ : technical development difficulty; $\mathrm{I}_{3}$ : uncertainty in technical life.

\subsection{Indexes construction of decision risk}

Decision risk refers to the risk that the enterprise leaders make mistakes or make decisions blindly. On one hand, although the leadership, experience and operational level of the high-tech enterprise managers are very high, some 
certaintechnological innovation in the decision-making errors may result in risk. One the other hand, it is the enterprise leader's own quality is not high, when the decision does not take scientific methods, see high technology content, the market potential of the new technology that can invest. He ignored the technology, human and financial conditions and management, technology innovation itself, resulting in new technology to develop their efficiency, even by using new technology to enable enterprises to bear a lot of debt, debt, suffered a great loss. Such examples in the real economic life are still a lot. Two indexes are selected to describe the decision risk. $\mathrm{I}_{4}$ : decision error; $\mathrm{I}_{5}$ : decision making ability.

\subsection{Indexes construction of market risk}

Technological innovation is a concept based on the needs of the market. And the market is sometimes difficult to accurately grasp, with uncertainty. The main reason is that the market needs to change rapidly with the change of environment. From the production of technological innovation, and then to be accepted by the market, there is often a time cycle. The length of the cycle is not very good. If this cycle is not allowed, it will bring risks to the enterprise. At present, the textile machinery new product updates faster, a variety of new materials and new technology are grafted to the textile machinery products, the performance of the product continuously improve. Innovation is not unique. The enterprise innovation is not purely a technical problem, as well as marketing issues. The price will also face fierce competition in the market. In the modern economic conditions, with the acceleration of information exchange, the speed of new technology diffusion is also accelerating. Therefore, it is very difficult to predict the acceptance of technical achievements. Innovation results in the market, what is the competitiveness, how much market share can be obtained, it is difficult to accurately determine the subject of innovation. This depends not only on the technology itself, whether the company has a good sales ability is the key factor of innovation success or failure. $\mathrm{I}_{6}$ : market needs; $\mathrm{I}_{7}$ : innovation acceptance; $\mathrm{I}_{8}$ : market competitiveness of innovation.

\subsection{Indexes construction of environment risk}

The environment risks include the risks brought by the natural environment and the social environment. Natural disasters directly affect the technological innovation activities of enterprises, so that the technological innovation activities of enterprises cannot be carried out. Policy risk is due to the whole or local economic policy of the government to change the direction, or the adjustment of policy intensity and lead to changes in market relations, the uncertainty of technological innovation. Such as the adjustment of the government's industrial policy may make technological innovation in the development of the industry was restricted to the development or application, the risk. Such as the adjustment of monetary policy, if it is because of currency and monetary tightening, the transformation of technological innovation, achievement of the enterprise may be caused by the lack of funds innovation activities cannot be carried out. The 
formation of environmentrisk indexes in this paper include $\mathrm{I}_{9}$ (the risks posed by the natural environment) and $\mathrm{I}_{10}$ (the risk of social environment).

\section{Risk prevention of technology innovation in high-tech enterprises}

\subsection{Strengthen awareness of investment risk}

Only having a strong sense of risk of business operators can correctly estimate the risk of technological innovation at all stages, and prepare for the challenge of risk. They recognize the nature of the risk in the process of innovation, clear the practical significance of the risk. Only with a sense of risk, in order to take effective methods and strategies to control risk, risk management, in order to be able to deal with risks, timely response to minimize the risk, to maximize the effectiveness of. Based on the collected data and estimate the possible risk, determine the lead to the conditions and factors, according to their own advantages and development technology, select some low risk gaps in the field of technological innovation. At the same time, in the choice of the project implementation process, we should choose a relatively low cost, shorter time of the implementation of the program, before and after the occurrence of the risk of a complete and thorough elimination of a possible risk of loss. The implementation of core technology strategy, in the direction of the core technology to carry out innovative activities, can reduce the cost of innovation research and production costs and uncertainty, thereby enhancing the innovation income. And has a strong core technology companies have the ability to develop new products faster, their product quality and reliability is relatively high, so as to have a stronger competitive edge. This enables enterprises to promote innovation in the market quickly, greatly reducing the risk.

\subsection{Strengthen recognition of investment risk}

According to the technical innovation investment risk control measures of high and new technology enterprises and the influence of different levels of risk on the development of enterprises. The overall effect is not significant, which can take the risk retention measures. According to the comprehensive evaluation result of risk retention or risk mitigation measures, the main task is to reduce the probability of risk occurrence to minimize the risk consequences, and change the nature of risk. The innovation in the process of project operation, project of accident management on the one hand, the project risk can be transferred to others by some technical means, such as through the joint enterprise development, contract transfer, business outsourcing, technology transfer, commissioned by the way of developing risk transfer, on the other hand can participate in insurance or insurance technology projects, through to the insurance company insured and transfer the risk to the insurance company on the body, or to attract investment risk in the project investment process. The process of innovation is a continuous learning process of innovative organizations, to adopt a flexible and effective 
organizational structure and organization. High and new technology enterprises should establish a good internal and external information flow mechanism to ensure the smooth progress of the innovation process. For a high tech enterprise, it is not necessary to use only one strategy mentioned above. In the practical application, the enterprise should select a set of risk early warning strategies on the basis of the identification, analysis and evaluation of the core staff's investment risk, the type of risk, the possibility of loss and the probability of occurrence. The enterprise should consider the systematic optimization of the combination of the early warning strategy of investment risk, and make the enterprise risk early warning to be optimized.

\section{Conclusion}

High tech enterprise is the main body of innovation activities in our country, and its development is directly related to the realization of the goal of innovative construction in our country. In this paper, the author analyses the first level index and the two level index of the investment risk of technological innovation. However, the risk of technological innovation investment in high-tech enterprises is a complex issue, which needs to be refined according to different regions and different industries. This is the focus of the future research.

\section{Acknowledgement}

The research was financially supported by National Social Science Foundation Project (Grant No. 15BGL144), Quality Engineering of Social Science Applications in Jiangsu Province (Grant No. 16SYC-016) and Philosophy and Social Science FoundationProject in Jiangsu Universities (Grant No. 2016SJD790029 and 2016JD630086).

\section{References}

[1] Liu Yao, Zhang Qian, Risk Early Warning Index System for Technological Innovation in Hi-Tech Enterprises, Journal of Shenzhen University (Humanities \& Social Sciences), 28(6), pp. 77-83, 2011.

[2]Li Huajun, Zhang Guangyu, RiskManagement Based on Psychological Contract for theHi-tech Enterprise'Intellectual Turnover, Science \& Technology Progress and Policy, 26(8), pp. 153-156, 2009.

[3] Min Jian, Zhang Youtang, Study on Positioning System of the Risk Early Warningfor Enterprise Overseas Investment, Finance and Accounting Monthly, (20), pp. 3-10, 2015.

[4] Wang Hui, Cai Chunfeng, Li Yinhai, ResearchonRiskEvaluationoftheTechnologicalInnovationProjectsforHitechEnterprisesBasedonFNN, (22), pp. 225-229+218, 2010 
[5] Gao Pan, On the Alienation of Technology and Technology Risk, Value Engineering, (11), pp. 241-244, 2016.

[6]MaoYajuan,LinTeng, ChengYijie, Risk Investment and High-tech EnterpriseDevelopment-

theExperienceandRevelationfromAustraliaandNewZealand, (35), pp. 114-118, 2016. 